\title{
An intervention to decrease time to parents' first hold of infants in the Neonatal Intensive Care Unit requiring respiratory support
}

\author{
Kaitlin M. Kenaley ${ }^{1} \cdot$ Annette L. Rickolt $^{1} \cdot$ Derek A. Vandersteur $^{1} \cdot$ Julia D. Ryan ${ }^{1} \cdot$ John L. Stefano ${ }^{1}$
}

Received: 10 May 2019 / Revised: 27 November 2019 / Accepted: 18 December 2019 / Published online: 7 January 2020

(c) Springer Nature America, Inc. 2020

\begin{abstract}
Background There are many barriers to parental skin-to-skin contact for critically ill neonates. Our aims were to decrease median time to first parental hold of neonates requiring respiratory support from 6.4 to 3 days, and to increase the percentage of neonates held within the first $24 \mathrm{~h}$ after birth from 6 to $75 \%$.

Methods Lean Six Sigma methodology was used to identify barriers to holding and opportunities for improvement. Intervention A multifactorial improvement bundle was implemented to reduce the time to first parental hold of critically ill neonates.

Results Median time to first parental hold was reduced from 6.4 to 1.2 days $(p<0.01)$. Infants held within the first $24 \mathrm{~h}$ after birth increased from 6 to $35 \%$. There was no increase in adverse events associated with parental holding.

Conclusions Implementation of an improvement bundle resulted in a significant reduction in time to first parental hold of infants requiring respiratory support.
\end{abstract}

\section{Introduction}

The primary component of kangaroo mother care (KMC) between a mother and her infant is frequent skin-to-skin contact (SSC) where the infant lies on the mother's bare chest in an upright position [1,2]. When used in premature and low birth weight infants in resource-limited countries, $\mathrm{KMC}$ has been shown to reduce infant mortality, improve thermoregulation, reduce nosocomial infection, increase rates of breastfeeding and reduce length of hospital stay $[1,3]$. In developed countries, SSC between infants and their parents has been shown to have additional health and psychosocial benefits. Studies have shown that SSC is an effective intervention to reduce autonomic responses to painful stimuli such as heel sticks and venipunctures [4-8]. One study demonstrated a reduction in serum and salivary cortisol after a heel stick in infants receiving SSC versus those undergoing the procedure in an incubator [9]. Additional reported infant benefits include improved cardiorespiratory stability, evidence

Kaitlin M. Kenaley

Kaitlin.Kenaley@ChristianaCare.org

1 Pediatrics/Neonatology, Christiana Care Health System, Newark, DE, USA of energy conservation with lower heart rate and activity levels, improved sleep organization and quality, and improved infant emotional regulation [10-16]. Reported parental benefits include improved mother-infant bonding, increased maternal and paternal confidence and satisfaction in the care of their infant, reduced stress and anxiety, and improved maternal emotional healing after the stress of a preterm delivery $[11,13,17-22]$.

While the benefits of parental SSC with their newborns have been well described, there are often significant barriers to consistently implementing this practice in the neonatal intensive care unit (NICU). Obstacles encountered by parents can include fear and anxiety surrounding holding their infant, concern regarding the clinical stability of their infant, maternal medical conditions, and insufficient time or resources [23-25]. Additional barriers encountered by clinicians include a desire to adhere to traditional newborn care practices, ambivalent attitudes toward skin-to-skin care, lack of recognition of the value of parental holding, difficulty achieving parental buy-in, concerns regarding adverse events due to clinical instability, lack of training, and lack of time and resources to facilitate parental holding [23-27]. Quality improvement efforts aimed at addressing these common barriers have been shown to be successful in improving utilization of parental SSC with their newborns in the NICU [28-31]. 
Several studies in resource-limited countries have investigated the effects of initiating early SSC as part of continuous KMC between mothers and preterm infants, generally within the first $24 \mathrm{~h}$ after birth. Results suggest additional benefits compared with later-onset KMC including further decreases in infant mortality, decreased weight loss in the first $48 \mathrm{~h}$ after birth, and increased exclusive breastfeeding at 6 months of age [32-34]. In developed nations, a Cochrane review found that early SSC between mothers and healthy newborn infants had a positive effect on breastfeeding at 1-4 months post delivery and blood glucose levels 75-90 min after birth [35]. The effects of initiating early parental SSC for ill infants or extremely preterm infants in developed nations are not well described. A study in Sweden found that the median time to first SSC between parents and extremely preterm infants in seven regional level 3 hospitals in Sweden was six postnatal days. Factors increasing time to first parental hold included lower gestational age, higher severity of clinical illness, and increased ventilator days [36].

To our knowledge, no studies to date have used quality improvement techniques to reduce the time to first parental SSC with infants admitted to the NICU in developed nations. In our institution, baseline median time to first parental hold of newborns admitted to the NICU who required continuous positive airway pressure (CPAP) or mechanical ventilation was 6.4 days. Only $6 \%$ of these infants were held within the first $24 \mathrm{~h}$ after birth. The aims of this quality improvement initiative were to decrease the median time to first parental hold of newborns admitted to the NICU requiring CPAP or mechanical ventilation by $50 \%$ from 6.4 days to 3 days, and to increase the percentage of infants held within the first $24 \mathrm{~h}$ after birth from 6 to $75 \%$ within 6 months.

\section{Methods}

\section{Context}

The NICU at Christiana Care Health System is a level 3 perinatal referral center located in Newark, Delaware with an average daily census of 50 infants and an average of 6500 births per year. Approximately 160 infants less than 1500 grams are admitted annually, and $90 \%$ of patients are inborn. Clinical providers in the NICU include 13 neonatologists, 12 neonatal-perinatal fellows, 22 neonatal nurse practitioners, and 44 rotating pediatric residents. The Christiana Care NICU employs approximately 100 neonatal nurses, 8 respiratory therapists, and 6 physical therapy/ occupational therapy providers. Prior to this quality improvement initiative, there was no formalized policy in our NICU regarding parental holding of their infant.

\section{Interventions}

To decrease the time to parents' first hold of infants in the NICU, a multidisciplinary quality improvement team was formed in 7/2014 that included two neonatal attendings, a neonatal fellow, a clinical nurse specialist, two neonatal nurse practitioners, two NICU nurses, two respiratory therapists, and an occupational therapist. Under the guidance of instructors of a Lean Six Sigma Green Belt course, our team performed a current state assessment and reviewed baseline data over a 6 month period from 1/2013 to 6/2013 that included time to first parental hold, adverse events that occurred during first parental hold, and number and type of invasive lines and respiratory support present during first parental hold. After reviewing the baseline data, our group developed our project aim statements as described above. We created a baseline process map depicting the steps necessary to achieve first parental hold to help our group better understand our unit's current process for parental holding and identify areas for improvement (Fig. 1). In addition, we conducted a parental survey to assess their expectations regarding holding their infant. We found a bimodal distribution for parental comfort of holding their infant with $45 \%$ of parents being either somewhat or very uncomfortable holding their infant and $45 \%$ of parents being either somewhat or very comfortable holding their infant. In contrast, when asked about their expectations regarding holding their infant, we found that $90 \%$ of parents either somewhat or very strongly agreed that they should hold their infant within the first $24 \mathrm{~h}$ after birth. Even though some parents expressed concerns regarding their comfort level with holding their infant, the majority of parents expressed interest in early parental holding.

Using a fishbone analysis (Fig. 2), we further investigated causes of delay in parental holding. Several vital root causes were identified, including variation in information given to families regarding holding their infant, inconsistent planning for parental holding, lack of staff understanding of benefits of first parental hold, lack of criteria for medical stability for holding, lack of family understanding of the benefits of SSC, decreased staff availability to assist with holding, and a bedside environment that is not conducive to parental holding.

To address the concern regarding a lack of an operational definition of medical stability for parental holding, we surveyed multiple care providers in the NICU including physicians, nurses, and respiratory therapists. They were provided with a list of medical conditions or equipment and were asked if they felt that parental holding with these conditions is appropriate. Fifty-five providers responded to our survey, and the results were used to create a Pareto chart (Fig. 3). Our staff agreed that infants with the following conditions or equipment were considered stable enough for 


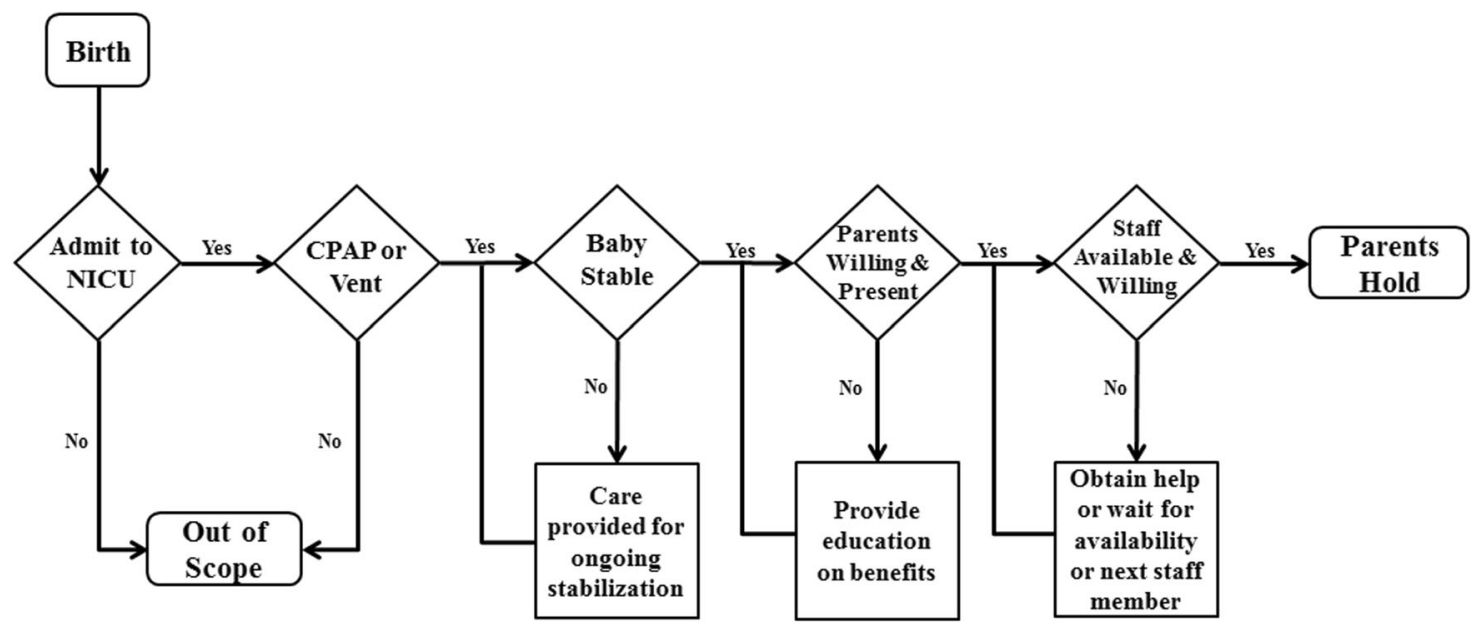

Fig. 1 Baseline process map depicting steps to achieve first parental hold of an infant admitted to the NICU requiring CPAP or mechanical ventilation.

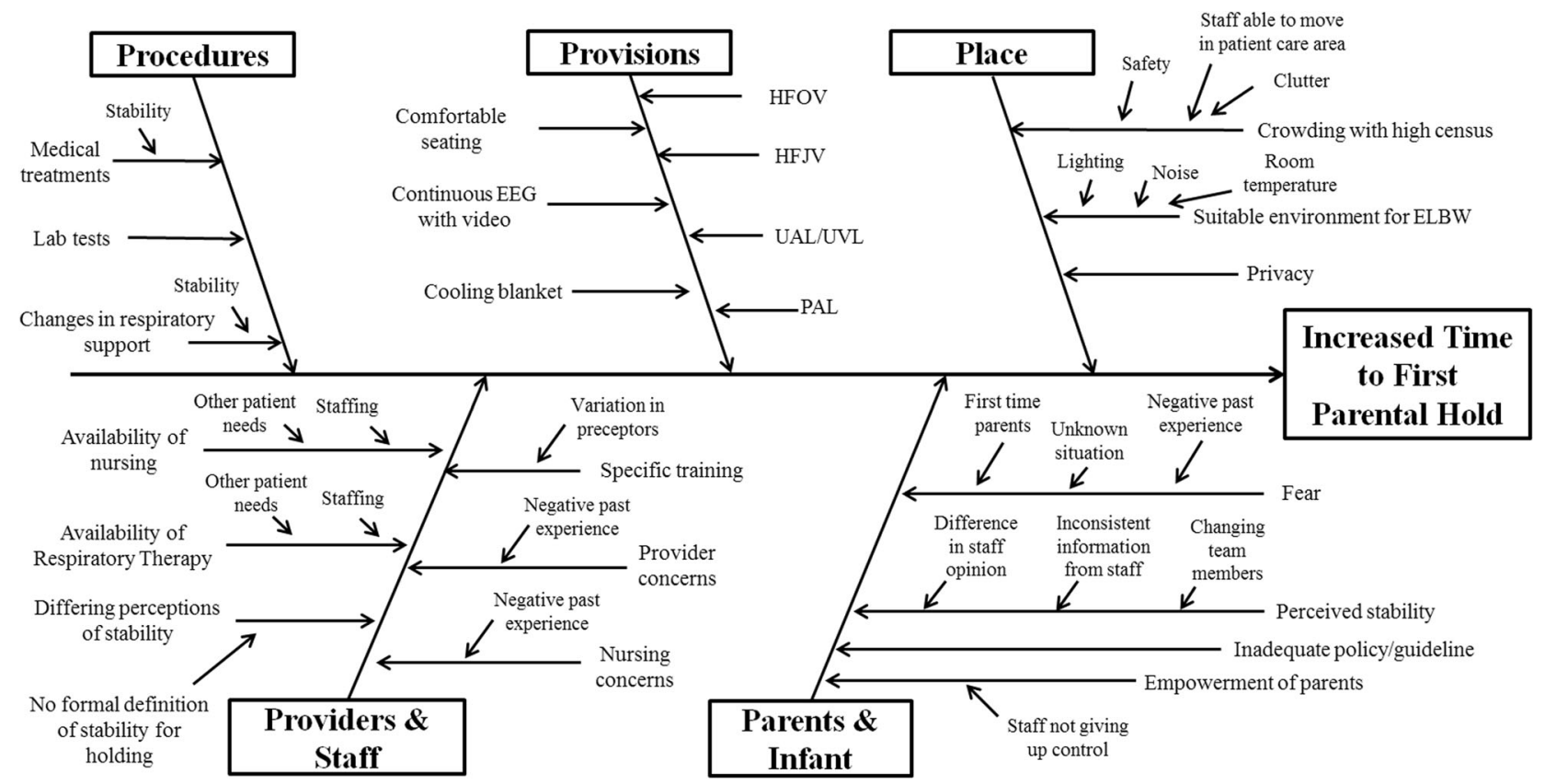

Fig. 2 Fishbone diagram depicting causes of increased time to first parental hold.

skin-to-skin care: $\mathrm{FiO} 2$ requirement greater than $45 \%$, umbilical venous and arterial catheter in place, peripheral arterial line in place, pressor infusions, and high frequency ventilation. Infants with a chest tube, who are receiving medications for paralysis, and infants with severe persistent pulmonary hypertension were felt to be medically unstable and not appropriate for parental holding until improvement in medical condition was demonstrated.

Our team used Lean Six Sigma methodology and tools including a $6 \mathrm{~S}$ tool, impact control matrix, failure mode effect analysis, and a barriers and aids chart to identify, highlight and prioritize opportunities for improvement. Several solutions to our problem were identified and implemented as two multifactorial quality improvement bundles. The first bundle, initiated in 7/2015, included: (1) Creation and distribution of educational pamphlets reviewing the benefits of SSC for both parents and staff; (2) Creation of a unit policy regarding parental SSC including a definition of medical stability for holding; (3) Initiation of appointments for first parental hold with visual display of appointment time on a bedside white board as well as through the use of appointment cards. The second bundle, initiated in 9/2015, included: (4) Introduction of early parental holding during NICU consults by neonatal attendings and fellows to introduce the concept of SSC prior to birth; (5) Streamlining of the bedside environment through use of a checklist for nursing staff to use to prepare the 
Fig. 3 Pareto chart depicting results of staff survey regarding attitudes toward medical stability for parental holding. $\mathrm{FiO} 2$ fraction of inspired oxygen, UVC umbilical venous catheter, PAL peripheral arterial line, UAC umbilical arterial catheter, HFJV high frequency jet ventilation, HFOV high frequency oscillatory ventilation.

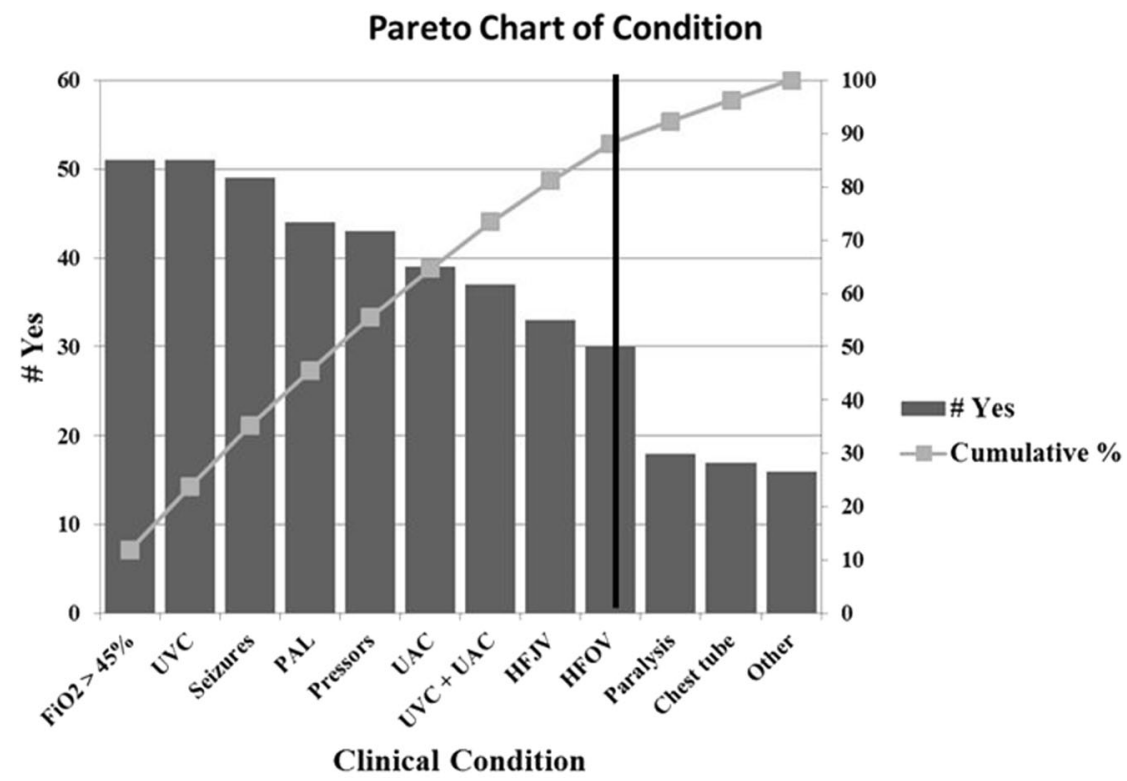

bedside for parents' first hold; and (6) Extensive staff education regarding the above improvement bundle and changes to unit policies regarding SSC. We created a future process map incorporating the above changes into the steps necessary to achieve first parental hold (Fig. 4).

\section{Measures}

The primary outcome measure for this quality improvement initiative was time to first parental hold after birth measured in days. In-scope patients included those admitted to the NICU requiring CPAP or mechanical ventilation who otherwise met the definition for medical stability as above. Infants of all gestational ages were included in this initiative. Infants receiving therapeutic hypothermia were excluded. Balancing measures included adverse events during first parental hold, respiratory support present during first parental hold, and number and type of invasive lines present during first parental hold. Adverse events during parental hold were defined as accidental extubation, dislodgement of a central line (including umbilical lines, peripherally inserted central catheter [PICC] lines, peripheral arterial lines), cardiorespiratory instability (significant bradycardia or desaturations), and hypothermia at the conclusion of the parental hold (temperature $<36^{\circ} \mathrm{C}$ ).

\section{Data analysis}

Outcome and balancing measure data were extracted from our electronic medical record on a biweekly basis. Statistical analysis was performed using Microsoft Excel (2010). Comparisons between pre- and post-intervention data were performed using Student's t-test for continuous data or chi-squared test for categorical data. The Pareto chart was created using Microsoft Excel (2010). The control chart was created using Minitab ${ }^{\circledR}$ Statistical Software (version 18.1; State College, PA:Minitab, Inc).

\section{Results}

Postintervention data were collected from 7/2015 to 12/ 2015. Fifty-two patients meeting inclusion criteria were analyzed during the baseline data collection period and 116 patients were analyzed during the postimplementation data collection period. Descriptive characteristics of the pre- and postintervention groups are summarized in Table 1. There were no significant differences in gestational age, type of respiratory support during first hold, and the presence of a central line during the first hold in the pre- and postintervention groups. More babies in the pre-intervention group had a PICC line present during first parental hold compared with the postintervention group, which we believe is secondary to the overall older age of these babies at the time of first hold. There was only one adverse event during our intervention period associated with first parental hold which was an unplanned extubation of an infant on high frequency oscillatory ventilation, compared with two adverse noted during baseline data collection (one episode of apnea and bradycardia requiring termination of parental hold and one episode of bloody secretions in the infant's endotracheal tube).

After implementation of our multifactorial improvement initiative, we saw a reduction of the median time to first parental hold from 6.4 to 1.2 days $(p<0.01)$ that exceeded our initial goal of a median of 3 days to first hold. We also 


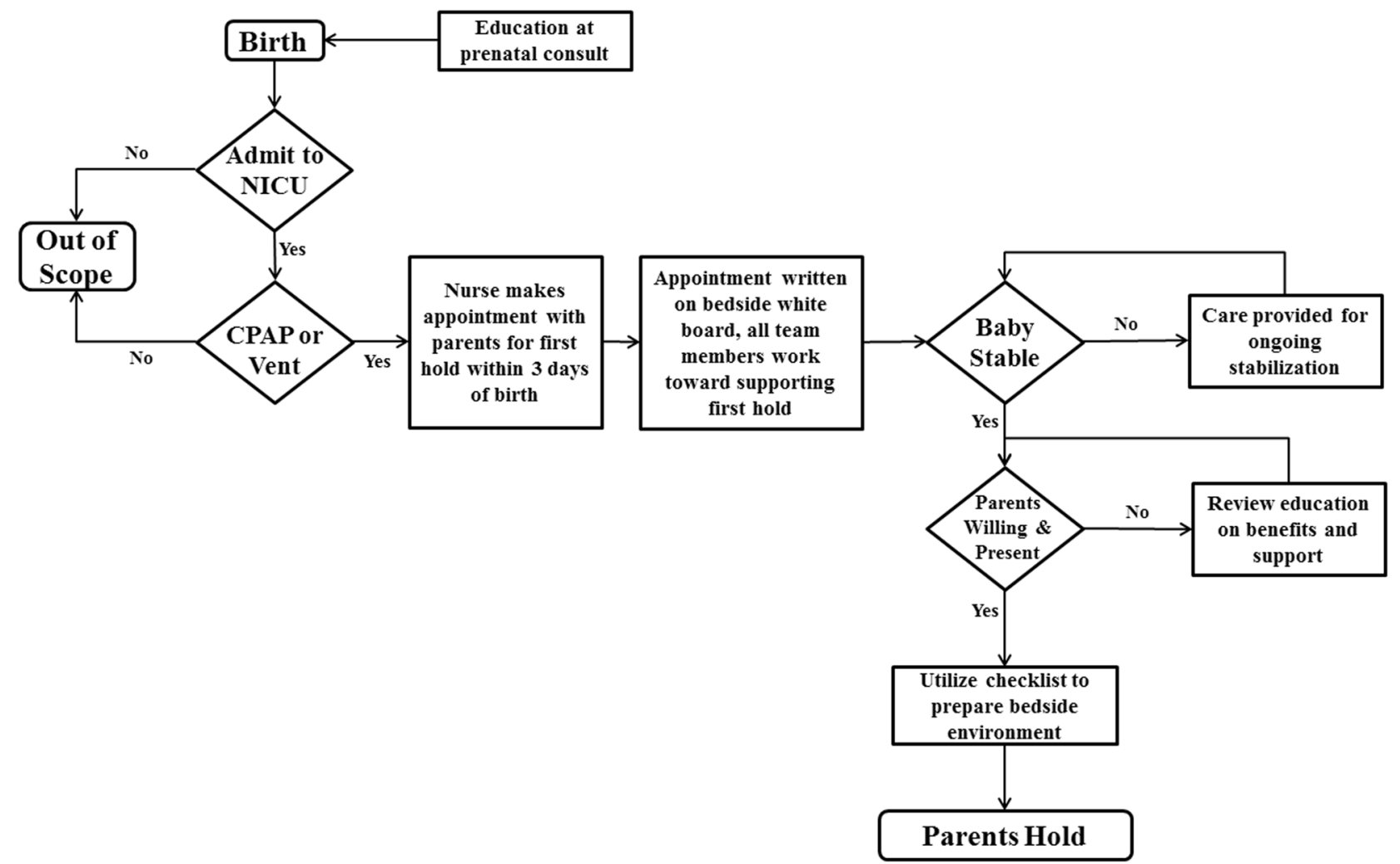

Fig. 4 Future state process map incorporating a multifactorial bundle aimed at reducing the time to first parental hold of infants admitted to the NICU requiring CPAP or mechanical ventilation.

Table 1 Descriptive characteristics of the pre- and post-intervention groups.

\begin{tabular}{lllr}
\hline & $\begin{array}{l}\text { Pre intervention } \\
(n=52)\end{array}$ & $\begin{array}{l}\text { Post intervention } \\
(n=116)\end{array}$ & $p$ \\
\hline $\begin{array}{l}\text { Gestational age } \\
\text { (weeks) }\end{array}$ & $30.4 \pm 5.1$ & $31.7 \pm 5.1$ & 0.12 \\
$23-28(\%)$ & $21(40)$ & $40(34)$ & 0.46 \\
$29-36(\%)$ & $20(39)$ & $52(45)$ & 0.44 \\
$37+(\%)$ & $11(21)$ & $24(21)$ & 0.95 \\
Intubated (\%) & $29(56)$ & $54(47)$ & 0.27 \\
Any central & $24(46)$ & $47(41)$ & 0.49 \\
line (\%) & & $42(36)$ & 0.09 \\
Umbilical line $(\%)$ & $12(23)$ & $5(4)$ & $<0.01$ \\
PICC line (\%) & $12(23)$ & $1(1)$ & 0.55 \\
Peripheral arterial & $1(2)$ & & \\
line (\%) & & & \\
\hline
\end{tabular}

demonstrated an increase in the number of infants held within the first $24 \mathrm{~h}$ after birth from 6 to $35 \%$ (Table 2). Analysis of our data over time showed a significant decrease in variation in time to first hold after implementation of our multifactorial improvement bundle (Fig. 5). After initiation of our improvement bundle, we saw a shift below the baseline median of 6.4 days to hold indicating special cause variation most likely attributable to our improvement initiative.

\section{Discussion}

Implementation of a multifactorial intervention using Lean Six Sigma methodology led to a significant reduction in the time to first parental hold for infants in our NICU requiring CPAP or mechanical ventilation from a baseline of 6.4 to 1.2 days. This goal was achieved without an increase in adverse events associated with parental holding. Our innovative improvement initiative encourages family-centered care by increasing parental participation in the care of their infant as well as collaboration with the health care team. An area of continued focus for our improvement team remains achieving our second goal of $75 \%$ of parents holding their infant within the first $24 \mathrm{~h}$ after birth. To our knowledge, ours is the first study reporting a quality improvement initiative that successfully decreased the time to parents' first hold of infants admitted to the NICU in a developed country.

A significant concern surrounding parental SSC in the NICU is the clinical stability of medically fragile infants, especially those requiring respiratory support. Multiple studies have demonstrated the safety and efficacy of 
Table 2 Outcome measures compared between pre- and post-intervention groups.

Fig. 5 Control chart of time to parental hold (days) for NICU patients requiring $\mathrm{CPAP}$ or mechanical ventilation. $\mathrm{UCL}=$ upper control limit (three sigma above the mean); $\mathrm{LB}=$ lower bound.

\begin{tabular}{llll}
\hline & Baseline & Goal & Post intervention \\
\hline Median time to first parental hold (Interquartile range) & 6.4 days $(3.1-9.6)$ & 3.0 days & 1.2 days* $(0.8-2.1)$ \\
Mean time to first parental hold (standard deviation) & $7.7( \pm 7.7)$ & - & $2.0^{*}( \pm 2.1)$ \\
$\%$ held within 24 h of birth & $6 \%$ & $75 \%$ & $35 \% *$ \\
\hline
\end{tabular}

$* p<0.01$

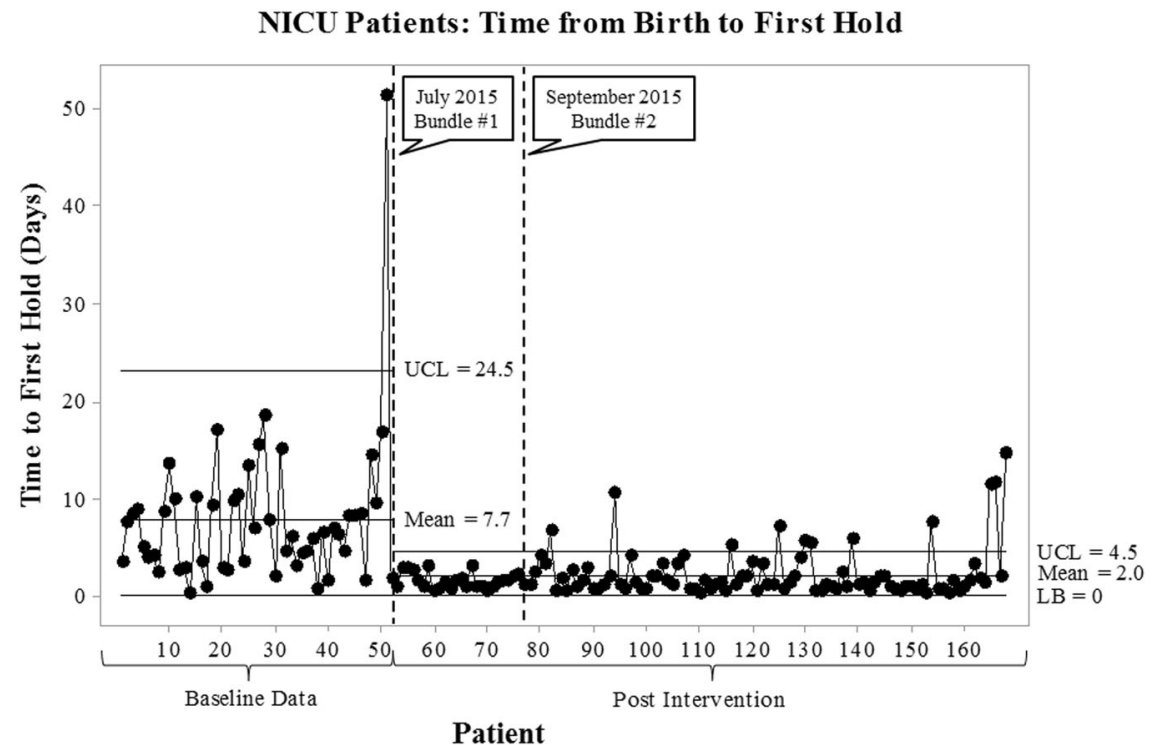

parental SSC in extremely preterm infants born at 22-26 weeks' gestation, infants requiring intubation and mechanical ventilation, and infants with other medical equipment such as umbilical catheters and nasogastric tubes $[22,37-45]$. The results of our quality improvement initiative are in agreement with these findings as our study was able to improve the time to first parental hold without an increase in adverse events. Creation of specific unit policies for parental SSC can facilitate safe and effective parental holding in the NICU. Close assessment of infant tolerance of SSC, monitoring of vital signs for physiologic stability, and standardized parental education for safe transfer of the infant between the incubator or crib and the parents' chest are of utmost importance. Formal unit policies regarding SSC can reduce variation in the information parents are given regarding timing and appropriateness of SSC, reducing miscommunication, and parental confusion. Additional guidelines to assist with development of unit SSC and KMC policies are published in the literature [38, 46-49].

Our group found that our NICU staff is very supportive of early parental holding, even for our sickest infants, and was responsive to our improvement efforts and new unit guidelines. In general, parents have been able to overcome their fear of holding sick infants with encouragement and education from staff. Our most important key to success was the creation of a multidisciplinary team involving different types of providers, including frontline staff of nursing, respiratory therapy and PT/OT who were responsible for ensuring the success of our interventions by increasing parental comfort with holding their infant. Our group identified several barriers to achieving parental holding within the first $24 \mathrm{~h}$ after birth, including degree of maternal illness that may impact ability to visit the NICU, lack of standardization of practice surrounding parental holding in the delivery room, and other ongoing NICU initiatives such as midline head positioning for VLBW infants for intraventricular hemorrhage (IVH) reduction. Next steps for our team will include increasing early holding by encouraging mothers to perform brief skin-to-skin in the delivery room immediately after birth, staff education regarding techniques for parental holding while maintaining the head in a midline position for VLBW infants, inclusion of a parent representative as a member of our quality improvement team, and implementation of video education on an iPad for parents demonstrating direct parental transfer of an infant from the bed to the parent's chest.

Our project has several limitations. We did not track rates of intraventricular hemorrhage (IVH) in our pre- and postintervention group patients. However, there was no significant change in the rates of IVH (both total and severe IVH) in our unit during our study timeframe (2013-2015) 
based on review of Vermont Oxford Network data for our NICU. It is unclear if our results will be generalizable to other NICUs with differing patient populations such as infants requiring more complex surgical interventions or extracorporeal membrane oxygenation. Our results were not stratified based on gestational age, and different strategies may be needed to improve rates of parental holding in ill term versus preterm infants. In addition, there is a large gap between our baseline data and postimplementation data collection periods secondary to constraints of the Lean Six Sigma course that guided our improvement team. It is possible that our NICU staff's behaviors and attitudes toward parental SSC began to change as a result of the formation of our improvement team and prior to initiation of our improvement bundle, especially given the long duration of baseline data analysis and planning prior to implementation of our interventions. However, despite this gap between baseline and postintervention data, we were able to demonstrate a definite change in staff attitudes toward parental SSC in our unit over time.

In conclusion, a multifactorial improvement bundle implemented in a level 3 perinatal referral center significantly reduced the time to first parental hold of infants admitted to the NICU requiring CPAP or mechanical ventilation. This improvement was accomplished without an increase in adverse events. The interventions implemented in this initiative could be used in other units caring for critically ill infants requiring respiratory support or with medical equipment such as central catheters and arterial lines. There are numerous potential health and psychosocial benefits for both parents and newborns to decreasing the time to first parental SSC. Quality improvement methods show great potential to improve this one facet of familycentered NICU care, and may be able to be applied to other areas of developmental care in the NICU.

Acknowledgements This research was presented in part at: (1) The Eastern Society for Pediatric Research Annual Meeting; Philadelphia, PA; March 2016. (2) The Annual Meeting of the Pediatric Academic Societies; Baltimore, MD; May 2016. (3) The Vermont Oxford Network Annual Quality Congress; Chicago, IL; September 2016. We would like to thank Gina Moore, RN, BSN, CPHQ for her assistance with data collection and analysis.

\section{Compliance with ethical standards}

Conflict of interest The authors declare that they have no conflict of interest.

Ethics This project was identified as a quality improvement project by the Christiana Care Health System Institutional Review Board and therefore was exempt from review.

Publisher's note Springer Nature remains neutral with regard to jurisdictional claims in published maps and institutional affiliations.

\section{References}

1. Díaz-Rossello JL, Conde-Agudelo A. Kangaroo mother care to reduce morbidity and mortality in low birthweight infants. Cochrane Database Syst Rev. 2014;22:CD002771.

2. WHO. Kangaroo mother care: a practical guide. Geneva: WHO; 2003.

3. Lawn JE, Mwansa-Kambafwile J, Horta BL, Barros FC, Cousens $\mathrm{S}$. 'Kangaroo mother care' to prevent neonatal deaths due to preterm birth complications. Int J Epidemiol. 2010;39 Suppl 1 : i144-i154.

4. Ludington-Hoe SM, Hosseini R, Torowicz DL. Skin-to-skin contact (kangaroo care) analgesia for preterm infant heel stick. AACN Clin Issues. 2005;16:373-87.

5. Cong X, Ludington-Hoe SM, McCain G, Fu P. Kangaroo Care modifies preterm infant heart rate variability in response to heel stick pain: pilot study. Early Hum Dev. 2009;85:561-7.

6. Cong X, Cusson RM, Walsh S, Hussain N, Ludington-Hoe SM, Zhang D. Effects of skin-to-skin contact on autonomic pain responses in preterm infants. J Pain. 2012;13:636-45.

7. Olsson E, Ahlsén G, Eriksson M. Skin-to-skin contact reduces near-infrared spectroscopy pain responses in premature infants during blood sampling. Acta Paediatr. 2016;105:376-80.

8. Johnston C, Campbell-Yeo M, Fernandes A, Inglis D, Streiner D, Zee R. Skin-to-skin care for procedural pain in neonates. Cochrane Database Syst Rev. 2014;23:CD008435.

9. Cong X, Ludington-Hoe SM, Walsh S. Randomized crossover trial of kangaroo care to reduce biobehavioral pain responses in preterm infants: a pilot study. Biol Res Nurs. 2011;13:204-16.

10. Scher MS, Ludington-Hoe S, Kaffashi F, Johnson MW, HolditchDavis D, Loparo KA. Neurophysiologic assessment of brain maturation after an 8-week trial of skin-to-skin contact on preterm infants. Clin Neurophysiol. 2009;120:1812-8.

11. Feldman R, Eidelman AI, Sirota L, Weller A. Comparison of skinto-skin (kangaroo) and traditional care: parenting outcomes and preterm infant development. Pediatrics. 2002;110:16-26.

12. Ludington-Hoe SM, Anderson GC, Swinth JY, Thompson C, Hadeed AJ. Randomized controlled trial of kangaroo care: cardiorespiratory and thermal effects on healthy preterm infants. Neonatal Netw. 2004;23:39-48.

13. Morelius E, Theodorsson E, Nelson N. Salivary cortisol and mood and pain profiles during skin-to-skin care for an unselected group of mothers and infants in neonatal intensive care. Pediatrics. 2005;116:1105-13.

14. Ludington-Hoe SM, Johnson MW, Morgan K, Lewis T, Gutman J, Wilson PD, et al. Neurophysiologic assessment of neonatal sleep organization: preliminary results of a randomized, controlled trial of skin contact with preterm infants. Pediatrics. 2006;117: e909-e923.

15. Ludington SM. Energy conservation during skin-to-skin contact between premature infants and their mothers. Heart Lung. 1990;19:445-51.

16. Weller A, Feldman R. Emotion regulation and touch in infants: the role of cholecystokinin and opioids. Peptides. 2003;24:779-88.

17. Chiu SH, Anderson GC. Effect of early skin-to-skin contact on mother-preterm infant interaction through 18 months: randomized controlled trial. Int J Nurs Stud. 2009;46:1168-80.

18. Johnson AN. The maternal experience of kangaroo holding. J Obstet Gynecol Neonatal Nurs. 2007;36:568-73.

19. Blomqvist YT, Rubertsson C, Kylberg E, Jöreskog K, Nyqvist $\mathrm{KH}$. Kangaroo mother care helps fathers of preterm infants gain confidence in the paternal role. J Adv Nurs. 2012;68:1988-96.

20. Cong $X$, Ludington-Hoe SM, Hussain N, Cusson RM, Walsh S, Vazquez V, et al. Parental oxytocin responses during 
skin-to-skin contact in pre-term infants. Early Hum Dev. 2015;91:401-6.

21. Helth TD, Jarden M. Fathers' experiences with the skin-to-skin method in NICU: competent parenthood and redefined gender roles. J Neonatal Nurs. 2013;19:114-21.

22. Tuoni C, Scaramuzzo RT, Ghirri P, Boldrini A, Bartalena L. Kangaroo mother care: four years of experience in very low birth weight and preterm infants. Minerva Pediatr. 2012;64:377-83.

23. Chan G, Bergelson I, Smith ER, Skotnes T, Wall S. Barriers and enablers of kangaroo mother care implementation from a health systems perspective: a systematic review. Health Policy Plan. 2017;32:1466-75.

24. >Smith ER, Bergelson I, Constantian S, Valsangkar B, Chan GJ. Barriers and enablers of health system adoption of kangaroo mother care: a systematic review of caregiver perspectives. BMC Pediatr. 2017;17:35.

25. Mangan S, Mosher S. Challenges to skin-to-skin kangaroo care: cesarean delivery and critically ill NICU patients. Neonatal Netw. 2012;31:259-61.

26. Vittner D, Cong X, Ludington-Hoe SM, McGrath JM. A survey of skin-to-skin contact with perinatal nurses. Appl Nurs Res. 2017;33:19-23.

27. Kymre IG. NICU nurses' ambivalent attitudes in skin-to-skin care practice. Int J Qual Stud Health Well-being. 2014;9:23297.

28. Hendricks-Muñoz KD, Mayers R. A neonatal nurse training program in kangaroo mother care (KMC) decreases barriers to $\mathrm{KMC}$ utilization in the NICU. Am $\mathrm{J}$ Perinatol. 2014;31:987-92.

29. Zhang SH, Yip WK, Lim PF, Goh MZ. Evidence utilization project: implementation of kangaroo care at neonatal ICU. Int $\mathrm{J}$ Evid Based Health. 2014;12:142-50.

30. Cooper L, Morrill A, Russell RB, Gooding JS, Miller L, Berns SD. Close to me: enhancing kangaroo care practice for NICU staff and parents. Adv Neonatal Care. 2014;14:410-23.

31. Stikes R, Barbier D. Applying the plan-do-study-act model to increase the use of kangaroo care. J Nurs Manag. 2013;21:70-78.

32. Nagai S, Andrianarimanana D, Rabesandratana N, Yonemoto N, Nakayama T, Mori R. Earlier versus later continuous kangaroo mother care (KMC) for stable low-birth-weight infants: a randomized controlled trial. Acta Paediatr. 2010;99:827-35.

33. Nagai S, Yonemoto N, Rabesandratana N, Andrianarimanana D, Nakayama T, Mori R. Long-term effects of earlier initiated continuous kangaroo mother care (KMC) for low-birthweight (LBW) infants in Madagascar. Acta Paediatr. 2011;100: e241-247.

34. Worku B, Kassie A. Kangaroo mother care: a randomized controlled trial on effectiveness of early kangaroo mother care for the low birthweight infants in Addis Ababa, Ethiopia. J Trop Pediatr. 2005;51:93-97.
35. Moore ER, Bergman N, Anderson GC, Medley N. Early skin-toskin contact for mothers and their healthy newborn infants. Cochrane Database Syst Rev. 2016;11:CD003519.

36. Mörelius E, Angelhoff C, Eriksson J, Olhager E. Time of initiation of skin-to-skin contact in extremely preterm infants in Sweden. Acta Paediatr. 2012;101:14-18.

37. Törnhage CJ, Stuge E, Lindberg T, Serenius F. First week kangaroo care in sick very preterm infants. Acta Paediatr. 1999;88:1402-4.

38. Ludington-Hoe SM, Ferreira C, Swinth J, Ceccardi JJ. Safe criteria and procedure for kangaroo care with intubated preterm infants. J Obstet Gynecol Neonatal Nurs. 2003;32:579-88.

39. van Zanten HA, Havenaar AJ, Stigt HJH, Ligthart PAH, Walther FJ. The kangaroo method is safe for premature infants under 30 weeks of gestation during ventilatory support. J Neonatal Nurs. 2007;13:186-90.

40. Azevedo VM, Xavier CC, Gontijo Fde O. Safety of kangaroo mother care in intubated neonates under 1500 g. J Trop Pediatr. 2012;58:38-42.

41. Karlsson V, Heinemann AB, Sjörs G, Nykvist KH, Agren J. Early skin-to-skin care in extremely preterm infants: thermal balance and care environment. J Pediatr. 2012;161:422-6.

42. Carbasse A, Kracher S, Hausser M, Langlet C, Escande B, Donato $\mathrm{L}$, et al. Safety and effectiveness of skin-to-skin contact in the NICU to support neurodevelopment in vulnerable preterm infants. J Perinat Neonatal Nurs. 2013;27:255-62.

43. Park H, Choi BS, Lee SJ, Son IA, Seol IJ, Lee HJ. Practical application of kangaroo mother care in preterm infants: clinical characteristics and safety of kangaroo mother care. J Perinat Med. 2014;42:239-45.

44. Bauer K, Uhrig C, Sperling P, Pasel K, Wieland C, Versmold HT. Body temperatures and oxygen consumption during skin-to-skin (kangaroo) care in stable preterm infants weighing less than 1500 grams. J Pediatr. 1997;130:240-4.

45. Maastrup R, Greisen G. Extremely preterm infants tolerate skinto-skin contact during the first weeks of life. Acta Paediatr. 2010;99:1145-9.

46. Jefferies AL. Canadian Paediatric Society, Fetus and Newborn Committee. Kangaroo care for the preterm infant and family. Paediatr Child Health. 2012;17:141-6.

47. Kledzik T. Holding the very low birth weight infant: skin-to-skin techniques. Neonatal Netw. 2004;24:7-14.

48. Nyqvist $\mathrm{KH}$, Expert Group of the International Network on Kangaroo Mother Care, Anderson GC, Bergman N, Cattaneo A, Charpak N, et al. State of the art and recommendations. Kangaroo mother care: application in a high-tech environment. Acta Paediatr. 2010;99:812-9.

49. DiMenna L. Considerations for implementation of a neonatal kangaroo care protocol. Neonatal Netw. 2006;25:405-12. 